\title{
Metals of a Changing World: Better Understanding the Metals Life-Cycles through a Holistic Approach
}

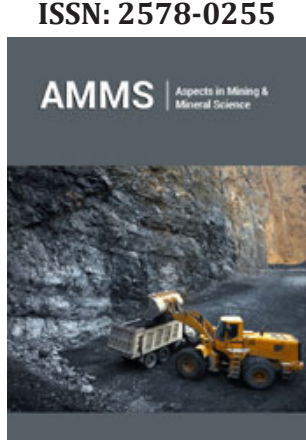

*Corresponding author: Michel Cathelineau, Université de Lorraine, CNRS, CREGU, Geo Ressources, Nancy, France

Submission: 制 September 04, 2020

Published: 比 December 15, 2020

Volume 5 - Issue 5

How to cite this article: Michel Cathelineau, Agnes Samper. Metals of a Changing World: Better Understanding the Metals Life-Cycles through a Holistic Approach. Aspects Min Miner Sci. 5(5). AMMS. 000625. 2020.

DOI: 10.31031/AMMS.2020.05.000625

Copyright@ Michel Cathelineau, This article is distributed under the terms of the Creative Commons Attribution 4.0 International License, which permits unrestricted use and redistribution provided that the original author and source are credited.

\author{
Michel Cathelineau* and Agnes Samper
}

Université de Lorraine, France

\begin{abstract}
The increasing need for metals announced for the next years as part of the energy transition effort cannot be counterbalanced by the recycled metals only. Understanding the natural, anthropic and environmental life cycles of metals must become a prerequisite to further extraction-to-manufacturing development projects, as part of a global reflection and effort for developing a circular economy, increasing low carbon energy production and protecting the biosphere.The full understanding of the future evolutions of both needs and resources, and their impact on the planet and life, needs interdisciplinary research. Besides, developing an excellent analysis of environmental, social, and governance factors related to mineral resource production will help make the right decisions at all levels.
\end{abstract}

Keywords: Metals; Modelling; Rare Earths crisis; Mining; Geological

Abbreviations: ETM: Energy Transition Metals; EIT: European Institute of Innovation and Technology; SLO: Social License to Operate

\section{Introduction}

World population growth, increasing urbanization and rapid technological change point to the need to ensure the supply of raw materials, as our societies and industries embrace their digital and ecological transitions. The significant consequence is the need for increasing quantities of mineral resources of great diversity (base metals, rare earth elements, minor metals, lithium). However, their supply has now been globally acknowledged as both environmentally and geo-strategically challenging. Following the 2012 rare earths ChinaJapan trade dispute, the concept of criticality was defined for a series of natural elements, mostly imported, identified as not easily substitutable by others in specific industries like high tech and energy transition [1]. Other recent crises, up to the current global pandemic, affect the supply and price market of rare earths and other raw materials, repeatedly highlighting the need to completely re-think our vision of the exploitation of the planet resources. The 2015 Paris climate agreement and call for action [2], the World Bank's Climate Smart Mining Facility (2020) [3], both support the transition to green technologies through a responsible and sustainable extraction and processing of minerals and metals, by minimizing carbon and materials footprints. In this general context, research initiatives and incentives at the national level or the continental scale as in Europe, have emerged to mitigate better the transition to low carbon energies, including the topic of the extraction of critical metals. Research programs were developed at the scale of Europe like the European Institute of Innovation and Technology (EIT) dedicated to Raw Materials, H2020, and national efforts such as those organized by DERA in Germany, and Laboratories of Excellence "LabEx" in France funded by the French National Agency for Research (ANR) such as Labex RESSOURCES21. This research initiative fills the gaps between disciplines through cross-disciplinary approaches and covers all aspects of the three life-cycles of metals: natural, industrial and environmental. The objectives of this paper are to present the original ways chosen by RESSOURCES21 to depict the metal life-cycles in their global context and to stimulate innovative research results and recommendations.

\section{A Three-Life-Cycle Vision of Metal Resources}

As an analogy to the vision of a mine-life cycle, we argue that exploring the specificities of some groups of critical metals from extraction to recycling through their "life-cycle" is a proper way to look at metals. It enables, in particular, characterizing their geological concentrations 
up to their industrial extraction, processing and interaction with the biosphere. It provides a clear vision of the natural to anthropic effects through space and time. It will facilitate recommendations for enhancing sustainability at every stage of their process for the benefits of both industries and communities. The natural geochemical life-cycle of metals extends to the industrial life-cycle, both of them having an impact on the biosphere: three cycles are thus used to illustrate the mutual interactions happening through the lifetime of a metallic particle (Figure 1).

\section{The first life-cycle of metallic elements: the natural geochemical cycle (ore genesis)}

The natural geochemical life-cycle of metals is a cycle that led to the concentration of metals as ores. It was concluded in the past and made up for the archives of the Earth. Understanding this natural enrichment within the lithosphere is essential as it relates to the prediction of the ore potentialities of the underground. This cycle regulates the processes from pre-concentration (in the source rocks), leaching by fluids and transport, deposition to accumulation as ore deposits, which can then be further affected by degradation and dispersion of their components, including metals (first circle of Figure 1). Some recent works have highlighted the relative failure of the mining industry's overall strategy, of not focusing on renewing reserves, as evidenced by the absence of recent discoveries of significant size for certain base metals such as copper [4]. The level of investment in prospection and exploration of brown or green areas proves to be very heterogeneous. Prospecting is thus much more sustained for refuge values such as gold rather than for metals more useful to the humankind, such as base metals like copper or the metals of the energy transition. The level of knowledge and the global understanding of the natural geochemical life-cycle of a given metal often remains too fragmented, in particular for the less known of the critical metals such as Tellurium (Te), Selenium (Se), Germanium (Ge), Indium (In), Rare Earth Elements (REEs), and in some respects Nickel (Ni), Cobalt (Co), Manganese (Mn), Niobium ( $\mathrm{Nb}$ ), Tantalum (Ta). For instance, how can we explain the presence of localized germanium or cadmium anomalies in only a small percentage of known zinc deposits? Or how does Tellurium distribute in a Gold-Arsenic-Bismuth (Au-As-Bi) geological province? In particular, what are the links between deposits and geodynamic events at a larger scale such as rifting, convergence, or paleoclimatic changes? Answering such questions would bring a better understanding of how ore deposits form and lead to the development of new useful geochemical exploration targets. New uses of geochronology techniques are necessary to establish correct temporal correlations, for instance, between ore processes and geodynamics.

When considering the improvements brought by the use of numerical modelling in the understanding of reactive transport and deposition at different scales, models still need to incorporate factors such as the complexity of the porous or fractured media and the cause of fluid migration (deep heat flow, intrusions). Numerical modelling development models remains rather heterogenous worldwide, and the use of such models to assess prospection objectives remains in its infancy. There do exist, therefore, several domains in which geoscientists can still bring new ideas for a better understanding of ore metallogenesis, and prompt new approaches and analytical tools such as non-invasive tools (drones, satellite). The development of IA, big data challenges could help better process the increasingly broad sets of data obtained with prospection tools and therefore facilitate future discoveries.

\section{The second life-cycle of metals: The industrial life-cycle}

Geometallurgy as the missing link between geology and process engineering?: A vast industrial domain develops from metal extraction to metal recycling, including mining, ore processing, refining, manufacturing. Connectedness between Geosciences, Engineering Sciences and Chemistry is critical to the optimization of processes in bringing solutions to emblematic issues of extraction and separation, as much as in contributing to reducing environmental impacts such as energy and water consumption, greenhouse gas emissions (Figure 1, circle 2). Moreover, the key to an optimized extraction would be to understand better the ore variability in deposits at the grain scale, as it would enable effective monitoring of ore processing throughout the plant. As the distribution of minerals may vary in the mill, flexibility to adapt processes to these variations is an already well-known challenge. Geometallurgy has progressively integrated a broad range of techniques and data management, including high-level mineralogy and petrology to further better consider the variability of ores. Recent research works attest of the dynamics of this new discipline in particular in Sweden, Germany and France [5-7].

Modern geostatistical approaches coupled to 3D geo-modelling also contribute to the renewal of approaches, in allowing routine three-dimensional characterization of ores but also predictive 3D models at the regional scale [8]. This "Novel Geometallurgy" proves to be efficient in the analysis of mineral grades and textures by the use of combined techniques [9-11]. It also contributes to improving the accuracy and understanding of spatial models with machine learning throughout ore processing procedures [12]. These novel coupled technologies embody the call for creating new synergies between disciplines previously kept through the traditional "mining silos" of geology, mining and mineral processing [13]. Overcoming such difficulties in a near-future will be critical to the production of the new emerging critical metals, which are often by-products of the main base metals, and for which developing co-beneficiation will then be essential. Creating an efficient and effective co-beneficiation in the mill will require excellent knowledge of speciation in mineral carriers, as well as to understand the relative distribution of the different metals occurring in the deposits. Up to today, most mining sites are still currently devoted to only one metal due to the difficulties and costs of integrating into the plant new separation processes for the accompanying metals. Extensive planning will, therefore, be required for implementing more responsible sustainable practices such as co-beneficiation. It seems necessary to optimize flow sheets (applied mathematics, geostatistics, artificial intelligence) and integrate the essential concepts of reduction of water and energy use, as well as waste reduction, to 
achieve a significant drop in mines' footprint in an overall goal of environment and biodiversity protection. Diversification in the production modes of mining plants could turn into one of the most significant challenges mining companies will have to face in a nearfuture. Recycling end-of-life products and recovering residues containing recoverable elements can help limit supply risks, as secondary resources cannot by themselves supply a country in full economic growth [14]. The increase in demand and consumption leads to increasingly large flows of metals but does not change the ratio between primary and secondary resource supplies, and even accentuates the imbalance between the number of raw materials produced to the mass of materials recycled.

Primary reserves can be renewed through two complementary mechanisms: first, the discovery of new large high-grade deposits, however more complex to exploit are more profound and more hidden, and their exploration requires advanced or breakthrough technologies; and secondly, the exploitation of existing deposits at much lower grades, less problematic in terms of exploitation constraints. These deposits benefit from an already existing territorial integration and tolerance by both authorities and local communities, and in terms of investment, from heavy infrastructures (underground or open-pit mining, processing plant) already profitable. Reserves usually presented in depletion calculations are calculated at the current market cut-off grade. However, if prices rise, it then becomes possible to mine at lower grades, but at tenfold higher energy costs [15]. The generalization of depletion calculations, therefore, comes up against the heterogeneity of cutoff grades for the same metal, and on the validity of the Skinner's concept of mineralogical barrier [16] which considers that metals cannot be exploited below a threshold.

\section{The third life-cycle of metallic elements depicts the interactions between metals, biosphere and atmosphere}

This cycle impacts the biosphere and atmosphere through the dispersion and accumulation of metals in the environment, whether they be of natural ( $1^{\text {st }}$ life-cycle $)$ or industrial/anthropogenic $\left(2^{\text {nd }}\right.$ life-cycle) origin. Estimating the environmental impact of metals' natural and anthropic dissemination on ecosystems, finding new methods for remediating disturbed environments (agromining, re-use of anthropized areas) and monitoring them (use of biogeochemical environmental sensors, ecotoxicology, genomics) have become strongly advised prerequisites to any mining project (Figure 1, circle 3). The latter include the reinforcement of laws and regulations, global improvement of impact assessment practices along the mine-life cycle, and an increasing tendency to work towards corporate image improvement through better environmental practices. However, too few mining areas have truly been the object of integrated environmental studies from geochemistry up to ecotoxicological reviews, as it has been the case during monitoring campaigns on polluted fields by radionuclide such as Chernobyl or uranium mine areas.

One example from our research group Labex RESSOURCES21 may be cited as it has developed an extended programme on the Rare-Earths geochemical cycles with a particular focus on the remediation and environmental issues of rare-earths extraction. The objective of the overall rare-earths project was to develop a complementary series of cross-functional multidisciplinary projects, which would encompass the life-cycle of Rare-Earths within the Earth's critical zone. One of the main workshop sites occurred in the second largest deposit of Rare-Earths in China, in a post-exploitation stage. There, the remediation initiative benefited from the humid-warm sub-tropical climate with original cultivation of Rare-Earths hyper-accumulating plants allowing Rare Earths to be extracted from polluted soils [17]. Specific efforts focused on understanding the speciation of trivalent elements in complex solution, their occurrence in contaminated soils and how to remediate them. Overall estimation of Lanthanide ecotoxicity was estimated from laboratory experiments [18]. Experiments in the lab led to evaluate Rare Earths tolerance and to the discovery that at the cell scale, the role of the plasma membrane appears as a hotspot for Rare-Earths toxicity $[19,20]$. These overall results give a better understanding of the impact of Rare-Earths mining on the environment and biosphere and have led to propose new ways for rare-earths remediation [21].

\section{Mining in a Global Economy}

\section{Crises and metal price fluctuations}

Metals of a changing world submitted to uncertainties, and financial fluctuation will still be, in the future, the attention of research, industry, political and public audience. The 2008 financial crisis, followed four years later by a more specific Rare Earths crisis, brought to the forefront of the media and of political discussions the topic of national independence in accessing mineral and energy resources. However, the interest fell back as soon as metal prices returned to more normal levels. The current pandemic seems to be turning this topic into a permanent interest, alongside the push towards renewable energies thanks to the Paris agreement of 2015 and this year's World Bank's Climate Smart Mining Facility initiative. Yet, how to turn global recommendations into real changes when a recurrent difficulty lies in applying innovative research results, as modifying existing plants has a cost that remains difficult to mitigate in the permanent fluctuation of metal prices. Another great difficulty lies here in the prediction of raw material markets as they much depend on speculation, unpredictable geopolitical events and an unregulated supply-demand system $[22,23]$. Such difficulty is enhanced in the case of precious metals $(\mathrm{Au}, \mathrm{Ag}, \mathrm{Pt}, \mathrm{Pd})$ which become more valuable in response to economic crises. For other metals, in particular minor metals, their prices and volatility are primarily dictated by shifting demand patterns and much less by supply constraints (Renner and Friedrich, 2019). Besides, as future demands will essentially be controlled by increasing urbanization alongside a rise in the total number of consumers, metal prices will also remain dependent on the evolution of technologies, yielding to volatility. For all these reasons, equilibriums are fragile, and even more, as the custom of keeping metal stocks seems to have been lost (Report on Stockpile Requirements, USA Sec. Dep. of Defense, 2015 [24]), thus removing a shock absorber for price fluctuations. The industry, nowadays essentially managed by financial experts, 
has found it very convenient in recent decades to buy on spot markets, thus breaking free from constraints about the security of supply or the constitution of strategic stocks. Unfortunately, one can ask themselves if a certain number of industry leaders have lost an awareness about managing their resilience, of if it has turned into a fashion of breaking free from a specific type of business responsibilities towards their employees and shareholder. Stockpiling does not seem to be in fashion anymore in the industry, and most analyses have shifted to the recommendations of Defence experts of each country.

\section{Society faced with paradoxical ambitions}

To reduce environmental impact and general consumption along with global development of new technologies for the greatest number, represent one of the main challenges our society has and will continue to face all along the implementation of its energy transition. As the greater community largely relies on communication technologies, it is brought to facing conflicting wills between, on the one hand, the desire for a cleaner planet through greener sources of energy and, on the other hand, the offer of a continued and even increased consumption. As exposed earlier, both of these conflicting prospects will inevitably imply the consumption of metals, and especially a 5 to $18 \%$ annual increase in the consumption of base metals over an estimated 30 more years throughout the implementation of infrastructures for renewable energy and public and individual transportation [4]. Under the current 2020 pandemic, a more critical call from civil society for more local and traceable medical drugs production chains has surfaced, rendered evident by the current situation. This strong call is already extending its application to all industry in general, including primary resources.

\section{Mining industry and civil society: The challenges of complex interactions and the opportunity of sustainability}

The mining industry and civil society at large, mining communities, in particular, have been facing growing challenges over the years. Firstly mining, with its high production pressure, remains one of the most hazardous occupations worldwide. Safety and health measures have been significantly improved. Although the industry itself is continually looking for improvement, mining remains the "bête noire" of the general public's perceptions, given the pressure and risks it poses to the environment. Secondly, potential impacts of large-scale mining projects to people have widely been reported through academic literature over the years and have also been pointed out by civil society organizations (CSOs) such as Oxfam, Amnesty International, Human Rights Watch, Mining Watch Canada [25]. Potential impacts include issues related to indigenous peoples, their cultural heritage, their employment, human rights, gender and development, equitable distribution of benefits, community development ([25] and references therein). In the last five years, two large-scale catastrophic mine waste dam failures have pointed out the vulnerability of communities and their environment to poor mining risk management. These events motivated the creation of international research consortiums to facilitate dialogue and research translation to industry, government, and civil society (e. g. Global research consortium on tailings, [26]). Such topics remain at the core of ongoing conflicts within existing mining communities or around mining exploitations to-be. Because socially-based conflicts can lead to the cessation of mining project development, difficulties during exploitation and decrease in productivity, conflicts pose a risk to the business in terms of costs. As outlined by [25], it can be considered that "the industry has a stated awareness of its potential to generate adverse social impacts, as the industry has been shown to prioritize risk when the cost to the business is obvious or high."

Therefore, industry's focus has remained intensively on the perception of the public towards mining activities and the risk they pose to their businesses, revealing the firm belief that public perception would be the main obstacle to contentious mining projects, and the key to a "social license to operate" (SLO) [27]. However, as outlined by [25], the mining industry considers social acceptability risk as equal to social risk, although social acceptability covers only partially the procedure of social risk assessment as it concerns people's perception about the riskiness of a project. SLO has now become itself a fierce topic of debate amongst stakeholders, which narratives have to be deciphered $[28,29]$. Following the goal of SLO, numerous studies and tools have emerged in the very recent years to identify, analyze, characterize and quantify better social risk, for all stakeholders. For example, based on the analysis of a significant number of mining projects, social risk indexes have been built in Quebec, Canada [30], on a global scale [31] or around the central theme of sustainability [32]. [33] conducted a further analysis of social risk indexes in Canada, by identifying the different characteristics of a project (open-pit or underground, distance to the community, unemployment rate) and by classifying them within three subsets relevant to stakeholders and their concerns (community, mining company, mining projects and their natural environment). Then, by considering those characteristics as factors that may affect the social risk of a mining project, they calculated an overall social risk score. Such social risk scores would bring further indications about the degree of social risk surrounding a designated project, to all stakeholders such as investors, mining companies, governments and communities. However, [33] concludes that "none of the characteristics part of the Social Risk Index can be considered as a definite indicator that a project has low or high social risk". Instead, the authors recommend a broader consideration of mining projects through the social patterns of the mining territory where they are set or planned to be, and advocate for looking at the general "socio-geological potential" of the mining territory as a whole [34].

Better territorial integration is also the approach developed by [35] for the gold mining sector in French Guiana. They propose a multi-criteria classification of all risks to systematically incorporate them into risk and impact assessments at the scale of the mining territory. The authors recommend a detailed preliminary analysis of mining projects up to their technical and operational characteristics, taken as decisive factors that will influence the nature and intensity of the potential impacts at various scales, and thus help make decisions at the territorial level, [36] also advocate for a broader 
vision to be integrated into future scenario planning about the transition to a low carbon future, by systematically considering in risk quantification, the environmental, social and governance (ESG) pressures surrounding the point of extraction (i. e. mining territories at large). The study presents a global assessment of ESG complexities associated with the extraction of Energy Transition Metals (ETM). By defining ETMs as 20 metal commodities including major metals such as copper, iron, aluminum, and critical elements such as nickel, cobalt, lithium, rare-earths and platinum, firstly they take into consideration the diversity of mineral resources needed for the energy transition, and secondly their complex extraction settings through seven dimensions of ESG risks (Waste, Water, Conservation, Land uses, Communities, Social vulnerability, Governance). The risk distribution across commodities worldwide points out the geographical areas of extraction that may be concentrating ESG risks in the race for future ETM supplies and outlines them as "Hot spots". In their analysis, "Cold spots" would represent extraction places of low ESG risks, hence countries, mining territories, jurisdictions with the ability to develop and maintain safeguards against ESG risks. In the various efforts of mapping all of the potential risks posed by a mining project in its immediate environment hence at the mining territory scale, some risks do not appear right at the beginning of a mining extraction but can also be "hidden" and only triggered when several other factors concur.
[25] name such dynamics of delays and potential interactions, "rebound". We have chosen to represent this rebound dynamics on (Figure 1) within a zone of interaction between society at large and the three mining cycles (ore genesis, impact on the biosphere, Industrial cycle). The size and shape of this area in (Figure 1) are shown to vary as a way of representation of this dynamic zone of interactions and interferences. Endl et al. [37] analyze the United Nations Sustainable Development Goals (SDGs) in the European context. Following the UN guidelines of SDGs, sustainability should be introduced at all scales and levels of the mining industry, with Innovation as one of the primary responses to mining challenges. Endl et al. [37] observe a two-direction drive that would be beneficial to a successful implementation of sustainability. The "inside-out" approach sees geology and economic viability as keys to success where safety, legislation and the environment are seen as the major constraints to the mining industry to be considered. The "outside-in" approach looks at mining within a broader, sustainability-driven, and societal perspective. The "outside-in" approach promotes innovations not only on technological levels but also societal, both aspects seen as critical drivers for enhancing sustainability in mining. We have also chosen to represent on (Figure 1) the areas of development and growth for sustainability within the space created by the public debate, through the insideout and outside-in approaches.

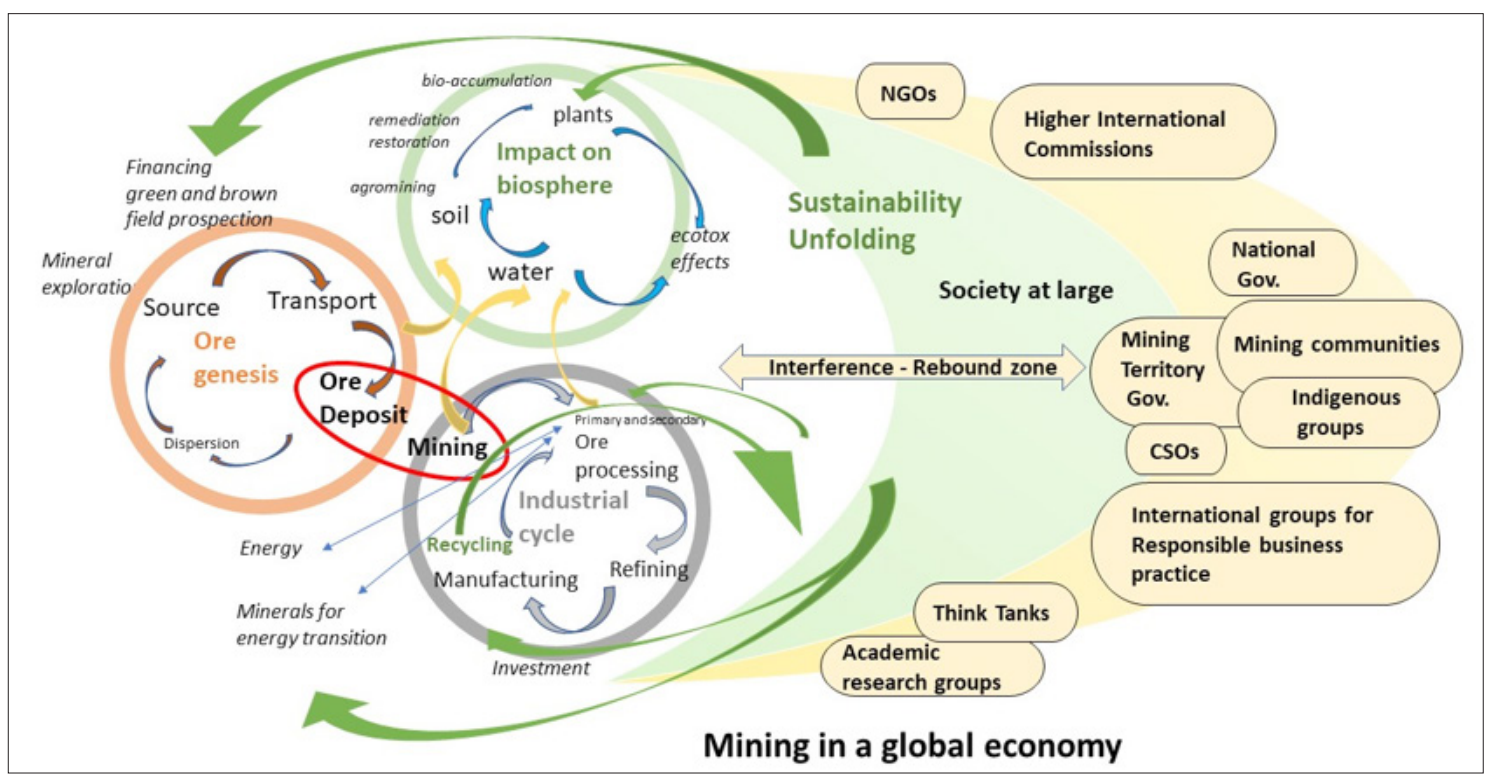

Figure 1: Mining in a global economy: the three metals life-cycles and their interactions with society at large. (NGO for non governmental organizations, CSO for civil society organizations, Gov. for governance).

\section{Conclusion}

The increasing needs of metals announced for the next 30 years as part of the energy transition effort cannot be counterbalanced by the recycled metals only. Highlighting the need to completely re-think our vision of the exploitation of the planet resources, the 2015 Paris climate agreement and call for action, and the World Bank's Climate Smart Mining Facility (2020) support the transition to green technologies through a responsible and sustainable extraction and processing of minerals and metals, which minimizes carbon and materials footprints. UN guidelines [38] and Europe's reflexion paper [39] place civil society at the heart of 17 sustainable development goals for 2030, including clean energy, sustainable cities and communities. We argue that there is a space in research for several types of cross-actions between disciplines for fully understanding the future evolutions of both needs and resources, and their impacts on the planet and life. These impacts will be 
either beneficial for the setting up of new modes of energy, or harmful if their understanding is not satisfactory. New visions, more integrated at the territorial scale, develop and already provide interesting tools for assessing vulnerabilities, hazards and risks, surrounding the extraction locations of mineral resources. More integrated, multi-organisms, cross-disciplinary initiatives could certainly significantly help to provide opportunities for better thinking and better planning resilient and sustainable extraction projects at the right scale, assisting stakeholders in making the right decisions at all levels. The Labex RESSOURCES21 is in line with the Paris Agreement to combat climate change and takes part in Europe's move towards greater sustainability in favour of a circular economy. This exciting project is part of a strategic research domain of the French Université de Lorraine (UL), ranked 11 for Mining and Mineral Engineering in the 2020 Shanghai ranking, making it first at the European level, and the unique group of research of its kind in France.

\section{References}

1. Jowitt SM, Mudd GM, Werner TT, Weng Z, Barkoff DW, et al. (2018) The critical metals: An overview and opportunities and concerns for the future; Society of economic geologists, Inc. SEG Special Publications 21: 25-38.

2. (2015) UNFCCC. Paris declaration on electro-mobility and climate change \& call to action. In Lima-Paris Action Agenda, USA.

3. (2020) World Bank. Climate-smart mining: Minerals for climate action, USA.

4. Vidal O, Goffé B, Arndt N (2013) Metals for a low-carbon society. Nature Geosci 6: 894-896.

5. Lund C, Lamberg P (2014) Geometallurgy -A tool for better resource efficiency. European Geologist 37: 39-43.

6. Foucaud Y, Badawi M, Filippov LO, Filippova IV, Lebègue S (2018) Surface properties of fluorite in presence of water: An atomistic investigation. The Journal of Physical Chemistry B 122(26): 6829-6836.

7. Lishchuk V, Pettersson M (2020) The mechanisms of decision-making when applying geometallurgical approach to the mining industry Miner Econ.

8. Rabeau O, Royer JJ, Jébrak LZ, Cheilletz A (2013) Log-uniform distribution of gold deposits along major Archean fault zones. Mineralium Deposita 48: 817-824.

9. Donskoi E, Manuel JR, Austin P, Poliakov A, Peterson MJ, et al. (2013) Comparative study of iron ore characterization using a scanning electron microscope and optical image analysis. Appl Earth Sci 122(4): 217-229.

10. Parian M, Lamberg P, Möckel R, Rosenkranz J (2015) Analysis of mineral grades for geometallurgy: Combined element-to-mineral conversion and quantitative X-ray diffraction. Miner Eng 82: 25-35.

11. Jardine MA, Miller JA, Becker M (2018) Coupled X-ray computed tomography and grey level co-occurrence matrices as a method for quantification of mineralogy and texture in 3D. Comput Geosci 111: 105-117.

12. Lishchuk V , Lund C, Ghorbani Y (2019) Evaluation and comparison of different machine-learning methods to integrate sparse process data into a spatial model in geometallurgy. Miner Eng 134: 156-165

13. Valenta R and Clark A (2019) Revisiting the Geometallurgy Road map, Procemin Geomet 2019, Santiago, Chile, 20-22 November 2019. Santiago, Chile: Gecamin Publications.
14. Labbé JF (2016) The physical limits of the contribution of recycling to the supply of metals. Annales des Mines Responsibility and the Environment 82: $45-56$

15. Northey S, Mohr S, Mudd GM, Weng Z, Giurco D (2014) Modelling future copper ore grade decline based on a detailed assessment of copper resources and mining. Resources, Conservation and Recycling 83: 190201.

16. Skinner BJ (1976) A second iron age ahead? American Scientist 64(3): 258-269.

17. Chour Z, Laubie B, Morel JL, Tang YT, Simonnot MO, et al. (2020) Basis for a new process for producing REE oxides from Dicranopteris linearis. Journal of Environmental Chemical Engineering 8(4): 103961.

18. Gonzalez V, Vignati DAL, Pons MN, Montargès Pelletier E, Bojic C, et al. (2015) Lanthanide ecotoxicity: First attempt to measure environmental risk for aquatic organisms. Environmental Pollution 199: 139-147.

19. Grosjean N, Gross EM, Le Jean M, Blaudez D (2018) Global deletome profile of Saccharomyces cerevisiae exposed to the technology-critical element yttrium. Frontiers in Microbiology.

20. Wehrmann M, Billard P, Martin Meriadec A, Zegeye A, Klebensberger J (2017) Functional role of lanthanides in enzymatic activity and transcriptional regulation of pyrroloquinoline quinone-dependent alcohol dehydrogenases in Pseudomonas putida KT2440. mBio 8(3): e00570- e00617.

21. Liu WS, van der Ent A, Erskine PD, Morel JL, Echevarria G, et al. (2020) Spatially resolved localization of lanthanum and cerium in the rare earth element hyperaccumulator fern Dicranopteris linearis from China. Environmental Science and Technology 54(4): 2287-2294.

22. Bosch D, Pradkhan E (2015) The impact of speculation on precious metals futures markets. Resources Policy 44: 118-134.

23. Algieri B, Leccadito A (2019) Price volatility and speculative activities in futures commodity markets: A combination of combinations of p-values test. Journal of Commodity Markets 13: 40-54.

24. (2015) Secretary of defense for acquisition, technology and logistics strategic and critical materials 2015 report on stockpile requirements. Dept of Defense, USA. p. 49.

25. Kemp D, Worden S, Owen JR (2016) Differentiated social risk: Rebound dynamics and sustainability performance in mining. Resources Policy 50: 19-26.

26. Global Research Consortium on Tailings. https://smi.uq.edu.au/ Tailings-Consortium

27. Thomson I, Boutilier RG (2011) Social license to operate. In: Darling P (Ed.), SME Mining Engineering Handbook. Society for Mining, Metallurgy and Exploration, Littleton, USA. pp. 1779-1796.

28. Boutilier RG (2020) Narratives and networks model of the social licence. Resources Policy 69: 101869.

29. Boutilier RG (2020) From metaphor to political spin: Understanding criticisms of the social licence. The Extractive Industries and Society.

30. Bergeron KM, Jebrak M, Yates S, Seguin C, Lehmann V, et al. (2015) Measuring the social acceptability of a mining project: An attempt to model social risk in the Quebec context. The Electronic Journal in Environmental Sciences 15(3).

31. Conde M, Le Billon P (2017) Why do some communities resist mining projects while others do not? Extr Ind Soc 4(3): 681-697.

32. Lindman A, Ranangen H, Kauppila O (2020) Guiding corporate social responsibility practice for social license to operate: A nordic mining perspective. Extr Ind Soc 7(3): 892-907.

33. Bergeron KM (2020) What can a hundred mining exploration projects in Canada tell us about social risk? Considering an area's trajectory to 
understand its sociogeological potential. The Extractive Industries and Society. https://doi.org/10.1016/j.exis.2020.09.004.

34. Forget M, Rossi M (2020) Mining region value and vulnerabilities: Evolutions over the mine life cycle. The Extractive Industries and Society. https://doi.org/10.1016/j.exis.2020.07.010.

35. Scammacca O, Gunzburger Y, Mehdizadeh R (2020) Gold mining in French Guiana: A multi-criteria classification of mining projects for risk assessment at the territorial scale. The Extractive Industries and Society. https://doi.org/10.1016/j.exis.2020.06.020

36. Lèbre É, Stringer M, Svobodova K, Owen JR, Kemp D, et al. (2020) The social and environmental complexities of extracting energy transition metals. Nat Commun 11: 4823. https://doi.org/10.1038/s41467-02018661-9

37. Endl A, Tost M, Hitch M, Moser P, Feiel S (2019) Europe's mining innovation trends and their contribution to the sustainable development goals: Blind spots and strong points. Resources Policy. https://doi. org/10.1016/j.resourpol.2019.101440.

38. (2015) UNGA, Transforming Our World: the 2030 Agenda for Sustainable Development, New York.

39. (2018) EC, Europe Reflection Paper Towards a sustainable Europe by 2030, New York. 